\title{
Marketing Viral: Uma Análise sobre seus Efeitos nas Decisões de Compra dos Consumidores Jovens
}

\author{
Charles Lindemberg Monteiro Dantas - charles.ufcg@gmail.com ${ }^{1}$ \\ Elmano Pontes Cavalcanti - elmanopc@gmail.com \\ Jaiany Rocha Trindade - rtjaiany@gmail.com
}

\begin{abstract}
Resumo - A contínua evolução das tecnologias, potencializadas pela internet, têm revolucionado o mundo dos negócios, impactando diretamente o comportamento das pessoas e como elas se socializam. Assim, surge um novo perfil de consumidor o "jovem", sempre conectado e influenciador, neste cenário, o marketing viral se apresenta como uma alternativa para as empresas se promoverem. O objetivo foi analisar a efetividade da influência do marketing viral na decisão de compra do consumidor jovem. Assumindo uma abordagem quantitativa de caráter descritivo, um estudo foi realizado junto a 53 jovens consumidores. Entre os principais resultados, destaca-se a utilização elevada da internet e do smartphone pelos respondentes; certa desconfiança com relação às propagandas em geral, motivando-os a reforçar suas opiniões através de informações da internet, e dos grupos ao qual pertencem, e uma maior propensão no compartilhamento de conteúdo. A conclusão geral é que a popularização das diversas Tecnologias de Informação, vêm impactando no comportamento e ocasionando um empoderamento do consumidor, isto implica que as empresas devem apresentar suas campanhas de maneira honesta, divertida e criativa, favorecendo a disseminação de conteúdo entre os grupos ao qual pertencem.
\end{abstract}

Palavras-chave: Marketing Viral, Internet, Consumidor jovem.

\section{Viral marketing: an analysis of its effects on the buying decisions of young consumers}

\begin{abstract}
The continuous technologies' evolution, powered by the internet, has revolutionized the business world, directly impacting people's behavior and how they socialize. Thus, a new consumer profile emerges, the "young person", always connected and influential, in this scenario, viral marketing presents itself as an alternative for companies to promote themselves. The objective was to analyze the effectiveness of viral marketing's influence on the purchase decision of young consumers. Assuming a quantitative approach of a descriptive character, a study was carried out with 53 young consumers. Among the main results, the high use of the internet and the smartphone by the respondents stands out; a certain distrust in relation to advertisements in general, motivating them to reinforce their opinions through information from the internet, and the groups to which they belong, and a greater propensity in sharing content. The general conclusion is that the popularization of the various Information Technologies, have been impacting on behavior and causing consumer empowerment, this implies that companies must present their campaigns in an honest, fun and creative way, favoring the dissemination of content between groups at the same time which they belong.
\end{abstract}

Keywords: Viral Marketing, Internet, Young consumer.

Data de Submissão: 14/06/2020

Data de Aceitação: 01/08/2020 


\section{Introdução}

O rápido desenvolvimento das tecnologias de comunicação da informação, representa uma grande revolução no mundo dos negócios. Os consumidores estão cada vez mais conectados e bem informados, as novas tecnologias vêm desafiando as empresas a se adaptarem a este cenário cada vez mais dinâmico na busca pela competitividade. Nesse sentido, é fundamental adquirir conhecimentos sobre os consumidores e assim identificar elementos influenciadores do comportamento virtual, decisão de compra e fidelização (STEINHOFF et al., 2018; SABAITYTE் et al., 2019).

O marketing é o grande responsável pela captação e retenção de clientes, fatores determinantes na geração de renda e crescimento das organizações (PRIDE; FERREL, 2016). Isso pode ser viabilizado através da difícil e incessante busca pela satisfação das necessidades dos consumidores, para criar e adaptar produtos e serviços que melhor se adequem a estes (RIES; TROUT, 2001; KOTLER; KELLER, 2012; REVELLA, 2015; GODIN, 2019).

As constantes mudanças na sociedade têm desencadeado novos comportamentos e hábitos de consumo nas pessoas. Os avanços tecnológicos eminentes, dentre estes a internet, tem sido responsável por grande parte dessas transformações, a exemplo das mídias sociais, que por sua vez, remodelam o modo de interação entre estas pessoas, reduzindo as barreiras geográficas e demográficas, bem como permitem o compartilhamento de suas experiências de consumo (KOTLER; KARTAJAYA; SETIAWAN, 2017). Com isso, a confiança do consumidor, outrora influenciada por campanhas tradicionais de marketing, volta-se a fatores sociais como: amigos, família, e seguidores de redes sociais, como o Facebook e o Twitter (JIN; RYU, 2019; SAMIEE, 2020).

Nessa onda de mudanças, surgiu o marketing viral, produzindo ações voltadas a divulgação espontânea de conteúdos por parte de seus expectadores, propagando-se rapidamente e atingindo outros consumidores; comparando-se a um vírus ou infecção humana (REICHSTEIN; BRUSCH, 2019; JENDOUBI; MARTIN, 2020). Assim, através do dinamismo da comunicação boca a boca potencializada pela internet, a curiosidade das pessoas é despertada, motivando o compartilhamento espontâneo de conteúdo através de suas redes sociais (TORRES, 2009).

Como consequência, emergiu um novo perfil de consumidor, “o jovem”, nativo digital e conectado, percebido por sua maior tendência à mobilidade e ao imediatismo das coisas. A este, surge uma característica marcante, confia em suas redes sociais, amigos e em familiares mais do que nas empresas (KOTLER; KARTAJAYA; SETIAWAN, 2017). Pesquisas revelam uma parcela considerável de usuários da internet formada por jovens; numa amostra de quase 180 mil pessoas entre diversas faixas etárias, $85 \%$ destes entre 18 a 24 anos acessaram a internet, sendo o smartphone o dispositivo mais utilizado, com cerca de 94,6\% (IBGE, 2016). Posteriormente, em uma nova pesquisa, esses resultados passaram para $88 \%$ e $97 \%$ respectivamente (IBGE, 2018).

Num cenário tecnológico e desafiador, emerge este perfil de jovem conectado, exercendo grande influência entre seus círculos sociais, ditando tendências e formando opiniões. No entanto, acompanhar estes avanços requer das empresas a adoção de técnicas cada vez mais eficazes, o marketing viral surge como uma importante alternativa, quanto a divulgação de suas marcas, aproveitando-se de seu efeito propagador, dinâmico e espontâneo. Dessa forma, o objetivo foi analisar a efetividade da influência do marketing viral na decisão de compra do 
consumidor jovem.

A compreensão dessa influência pode trazer diversas contribuições, entre estas: entender o consumidor na era digital; dimensionar o impacto do marketing viral na decisão de compra do consumidor jovem; apoiar o direcionamento de marketing das organizações; e proporcionar insights para futuras pesquisas. Portanto, o estudo se justifica.

\section{Conceitos}

O marketing tem experimentado uma série de transformações ao longo dos tempos, tanto sob uma perspectiva conceitual, como também no âmbito comercial. Dentre as diversas forças que vêm ocasionando essas mudanças, os avanços tecnológicos, em particular, têm um impacto profundo, resultando no aprofundamento do relacionamento com os clientes (FRANCISCO et al., 2019). O desenvolvimento exponencial dessas tecnologias expande ainda mais as suas possibilidades, aumentado a competitividade nos negócios, resultando em atividades cada vez mais eficazes (SABAITYTÉ et al., 2019).

Entre diversos estudos com esse foco: O impacto da tecnologia nas estratégias de marketing (CAPON; GLAZER, 1987; BLATTBERG; GLAZER; LITTLE, 1994); As abordagens sobre a geração de grandes volumes de dados, resultando em construções de modelos matemáticos para catalogar generalizações empíricas (BASS, 1993; LEEFLANG; WITTINK, 2000); O declínio da grande mídia ocasionado pela TV à cabo e outras tecnologias personalizáveis (KRUGMAN; RUST, 1993); A constante evolução da Internet e de outras modernas tecnologias da informação vêm possibilitando relacionamentos mais profundos e centrados nos clientes (WINER, 2001; RUST; MOORMAN; BHALLA, 2010; RUST; HUANG, 2014).

As inovações têm influenciado diretamente nas estratégias de marketing para conquistar a preferência e fidelidade dos consumidores. O que por sua vez, tem permitido às organizações uma melhor compreensão quanto ao comportamento desses, obtendo uma melhor assertividade na personalização e no direcionamento de conteúdos (BAIERLE et al., 2019; SANTOS, 2019). Como resultado, as inúmeras ferramentas da Tecnologia de Informação, a exemplo da Inteligência Artificial (IA), Big Data Analytics (BDA), Internet, entre várias outras, vêm fazendo com que os 4 Ps do estilo 1960 fiquem cada vez mais obsoletos (RUST, 2020).

A utilização da IA afetará diretamente a estratégica, incluindo modelos de negócios, processos de vendas e opções de atendimento, bem como possibilitará um maior conhecimento sobre o cliente e suas preferências, realizando uma personalização mais eficaz (DAVENPORT et al., 2019; IANSITI; LAKHANI, 2020). O BDA, por sua vez, vem permitindo uma análise mais profunda e assertiva quanto as necessidades dos consumidores, impulsionando a capacidade das organizações de criar produtos e entregar programas de marketing que atinjam níveis mais altos de satisfação (MSI, 2016).

No entanto, foi graças ao advento da internet que essas e muitas outras oportunidades surgiram, à medida que a quantidade de informações capazes de ser comunicadas seguem em crescimento exponencial.

Com o surgimento e o desenvolvimento da Internet como o principal canal e a melhor oportunidade para a implementação do modelo de marketing "one-to-one", o mercado tem se 
tornado mais interativo, oferecendo produtos e serviços de forma dinâmica e inovadora, além de permitir uma maior proximidade com os consumidores (KOTLER; KATAJAYA; SETIAWAN, 2017). Por outro lado, o poder e a atratividade do ambiente online também transformaram a maneira como esses se comportam, criando novos padrões e estilos de vida que devem ser levados em consideração ao criar estratégias apropriadas de marketing na internet, muito diferentes das tradicionais (GRUBOR; JAK ̌̌A, 2018). Nessa lógica, estar atento as mudanças na era digital é primordial para as empresas, o contrário pode significar o fim dos negócios.

Estar atento resulta na incessante busca pelo sucesso e em última instância, a sobrevivência, a qual, torna-se de suma importância, ir sempre aproveitando da melhor forma possível as ferramentas da TI que vão surgindo. Em termos globais, houve um aumento do número de sites de 17 milhões em 2000 para 1,78 bilhões em 2020 (INTERNET LIVE STATS, 2020). Esse crescimento, a tornou o principal campo de negócios e o canal de comunicação mais popular, criando novas regras e novos papéis (GRUBOR; JAKŠA, 2018).

A constante expansão da internet, demonstra por si só a sua importância. Aproximadamente $40 \%$ da população mundial possuía conexão com a internet no ano de 2018, em 1995 era menor que 1\% (AHLGREN, 2020). Atualmente, 59,6\% da população mundial, aproximadamente 4,6 bilhões de pessoas estão conectadas; no Brasil, esse percentual chega a 70,7\%, cerca de 149 milhões (INTERNET WORLD STATS, 2020). Assim, motivado pelas crescentes forças da internet, o aprofundamento do relacionamento entre as pessoas ampliou a capacidade e a necessidade das empresas de se comunicarem com os seus clientes, armazenar e analisar suas informações (RUST, 2020).

Além das inúmeras contribuições, a internet trouxe diversas inovações para a sociedade, entre estas, a possibilidade de que qualquer um possa ser o produtor, o intermediário e o usuário de conteúdo. Isto possibilitou a formação de redes de informação, onde os indivíduos se agrupam a seus semelhantes e estabelecem relações de interesse (MARQUES; VIDIGAL, 2018).

Este crescimento trouxe consigo um mundo de novas perspectivas, onde o consumidor conectado passa a ter maior poder e acesso às informações, impulsionando sua opinião que ganha maior força nas mídias sociais (KOTLER; KARTAJAYA; SETIAWAN, 2017). Através destas, grupos compartilham experiências de consumo, questionam marcas, elogiam e passam a escolher produtos ou serviços embasados nas avaliações de pessoas contidas em seus círculos sociais de confiança (AL ABRI; VALAEE, 2020).

Observa-se ainda um grande aumento de usuários das redes sociais, como demonstrado pela We Are Social (2020), onde 321 milhões de pessoas criaram um perfil em alguma dessas mídias, entre os anos de 2019 e 2020 . Ainda segundo a pesquisa, a proporção de pessoas que utilizam redes sociais em relação à população mundial é de $49 \%$, totalizando cerca de 3,8 bilhões de pessoas. Além disso, constatou-se que o tempo médio de permanência diária nessas redes, corresponde a $2 \mathrm{~h}$ e $24 \mathrm{~min}$, um valor bem alto levando considerando que a média diária de uso da internet é de $6 \mathrm{~h} 43 \mathrm{~min}$. Esses dados evidenciam o comportamento em rede, peculiar ao ser humano, onde ele se agrupa a seus semelhantes e estabelece relações de interesse, sejam elas de trabalho ou não, que se desenvolvem e se modificam conforme sua trajetória (MARQUES; VIDIGAL, 2018). 
A expansão de usuários online e móveis em todo o mundo, está impactando diretamente o comportamento do mercado, as vendas de e-commerce estão constantemente aumentando, as opções de remessa e pagamento foram simplificadas e as principais marcas globais foram introduzidas em novos mercados internacionais (LIPSMAN, 2019).

Após melhorias na tecnologia móvel, juntamente com as mídias sociais, o marketing se estabeleceu em um ambiente de mercado novo, complexo e desafiador. As redes sociais vêm impactando muitos aspectos da vida dos indivíduos, com quem eles discutem e, consequentemente, com quem podem influenciar suas opiniões sobre diferentes questões (AL ABRI; VALAEE, 2020). Realizar marketing através de redes sociais, exige das empresas uma maior transparência, elas devem ganhar a confiança e a credibilidade dos seus clientes, através de novas abordagens e técnicas de marketing; além de oferecer a oportunidade para alcançar o máximo de resultados com o mínimo investimento (GRUBOR; JAKŠA, 2018).

Recentemente, a popularidade das redes sociais online e sua crescente influência na formação e opinião das pessoas levaram os anunciantes a utilizá-las como uma plataforma de marketing, facilitando a interação cliente-cliente, bem como a interação cliente-empresa, o que resultou no aumento da importância do marketing viral (AL ABRI; VALAEE, 2020; RUST, 2020).

A comunicação é algo característico do ser humano, através de conversas formais ou não, as pessoas trocam ideias e compartilham suas experiências de forma espontânea. Deste modo, elas acabam por influenciar, ou são influenciadas em suas decisões de consumo. Em consequência disso, o marketing boca a boca surge como uma ferramenta que pode ser utilizada por profissionais da área de marketing e que exerce grande influência no comportamento dos consumidores (LÓPES; SICILIA, 2013).

As recentes mudanças no comportamento das pessoas, resultante dos avanços da internet e da expansão de novas mídias facilitou o desenvolvimento e o gerenciamento de campanhas boca a boca (FARD; MARVI, 2020). As redes sociais, incentivam a liberdade de opinião das pessoas, nelas expressam suas experiências, positivas ou não e que, quando provindas de um círculo de confiança, têm maior poder de influenciar e recomendar por produtos ou serviços (AL ABRI; VALAEE, 2020).

Neste cenário dinâmico, imprevisível e em crescimento constante, viabilizado pela internet e as mídias sociais e potencializado pelo efeito "boca a boca eletrônico" (eWON), surge o marketing viral (JENDOUBI; MARTIN, 2020). Trata-se de um conjunto de ações de marketing digital que visam criar uma grande repercussão da sua mensagem, permitindo atingir muitas pessoas que a retransmitem, semelhante a um vírus (LÓPES; SICILIA, 2013; REICHSTEIN; BRUSCH, 2019; FARD; MARVI, 2020; JENDOUBI; MARTIN, 2020). Assim, o marketing viral é criado por empresas e eWOM é criado por consumidores, sendo assim, o marketing viral é a causa e o eWOM é o efeito (FARD; MARVI, 2020).

Este tem se caracterizado como uma ferramenta que influência diretamente na competitividade dos negócios, motivando e facilitando a comunicação entre consumidores e empresas (LÓPES; SICILIA, 2013). Neste sentido, Kotler, Kartajaya e Setiawan (2017) ressaltam que para obtenção de melhores resultados estratégicos, as empresas precisam buscar a participação de grupos externos e aumentar o envolvimento de seus clientes no processo. 
Utilizar o relacionamento social para influenciar a opinião das pessoas é crucial para uma estratégia de marketing viral eficaz (AL ABRI; VALAEE, 2020). Nessa perspectiva Dinh et al. (2014), apresentam dois modelos de estratégia de difusão de informações: limiar e cascata. No modelo de limiar, atribui-se um peso para quantificar a capacidade de influência de uma pessoa sobre as outras, um Youtuber é um bom exemplo desse modelo. Quanto ao modelo de cascata, cada usuário ativo pode influenciar outros usuários e assim sucessivamente. No entanto, Al Abri e Valaee (2020) propõem um novo modelo de difusão ainda mais completo que leva em consideração ambos os modelos e a presença do usuário em várias outras redes.

A potencialidade dessas estratégias, demonstram como as empresas podem adquirir vantagem por meio das mídias sociais para anunciar suas marcas sem gastar muito, através da aplicação do marketing viral (FARD; MARVI, 2020). Usar comunicações "peer-to-peer" nos relacionamentos cliente-empresa para compartilhamento de informações sobre um produto é o principal objetivo da publicidade viral, resultando em aceitação do mercado (HO; DEMPSEY, 2010). Sobre a origem das comunicações, Bickart e Schindler (2001) encontraram um achado interessante, constataram empiricamente que as informações obtidas sobre produtos em discussões de usuários online despertam mais interesse do que as informações fornecidas pelas próprias empresas.

Consequentemente, o marketing viral requer interações sociais com foco nos produtos e serviços oferecidos, atraindo a atenção dos usuários, influenciando direta ou indiretamente a intenção de compra dos consumidores (FARD; MARVI, 2020). No entanto, algumas considerações são relevantes sobre o marketing viral, primeiro, por estar associado ao comportamento humano, pode se tornar algo imprevisível ou ainda difícil de controlar, o que nem sempre pode ser favorável à empresa (CAVALLINI, 2008).

Segundo, a facilidade de propagação de um determinado conteúdo pode fazer de um cliente insatisfeito, um disseminador de imagens negativas da empresa e em questão de segundos prejudicar sua reputação (MORICI, 2013). Assim, para evitar problemas como este, o conteúdo repassado deve ser verdadeiro e ao mesmo tempo impactante.

Ações como essas devem ser bem planejadas, para que o seu efeito seja positivo. Por isso, grande parte das empresas utilizam a eWOM dos líderes de opinião em suas campanhas para vendas de produtos e serviços desejados, e depois os incentivam a comunicar informações aos seus seguidores (JIN; RYU, 2019).

Neste cenário, destaca-se este novo perfil de consumidor, o jovem. Nascido na era digital, muitas vezes líder de opiniões, sempre conectado, encontra-se em fase altamente produtiva e é difícil de impressionar. Possui habilidade em conectar-se e compartilhar informações, comentários, avaliações sobre produtos e marcas (KOTLER; KARTAJAYA; SETIAWAN, 2017).

Sobre esse público: 88\% dos jovens entre 18 e 24 anos acessam a internet (IBGE, 2018); 98\% dos jovens de 15 a 29 anos utilizam o smartphone (FTV, 2019). Ainda, 100\% dos respondentes afirmaram que utilizavam a internet para a comunicação, com frequência média de 6,2 dias/ semana, e as principais redes sociais conectadas eram: WhatsApp (1), Instagram (2), Facebook (3) e Youtube (4). Assim, motivados pela constante ascensão no mercado e ao perfil conectado inerente aos jovens, os profissionais de marketing têm voltado sua atenção para esse público. 
A conectividade e a constante interação possibilitada pela Internet, tem afetado diretamente as decisões de compra desses consumidores conectados, suas escolhas têm sido cada vez mais influenciadas pelos seus contatos sociais (KOTLER; KARTAJAYA; SETIAWAN, 2017). Por meio destas mudanças e, com o intuito de adequá-lo a este novo caminho percorrido pelo cliente conectado, os autores apresentam o modelo conhecido como 5As (assimilação, atração, arguição, ação e apologia).

A fase de assimilação consiste no primeiro contato de comunicação com os clientes, como ele assimilará a imagem da marca ou reconhecê-la. Em seguida os clientes filtram àquelas mais relevantes, que mais os atraem, esta é a fase de atração e segundo os criadores do modelo os jovens estão entre os primeiros a reagir, sendo os primeiros a adotar novos produtos e tendências. Na fase de arguição, os conselhos de amigos, avaliações online, pesquisas e se forem convencidos por estas informações adquiridas, irão à fase de ação, que não se resume somente ao ato de comprar, as empresas devem estar atentas ao pós venda, interagindo com o cliente e certificando-se de sua satisfação. Por fim, os clientes podem retornar às marcas, evidenciando fidelidade e defendendo-a perante seus contatos, esta é a fase de apologia, onde clientes se tornam advogados das marcas, recomendando-as de forma espontânea e propagando conteúdos diversos, de forma viral (KOTLER; KARTAJAYA; SETIAWAN, 2017).

Para isso, os estudos de Fairbank (2008), Jakobsen e Skov (2009) e o de Xavier e Summer (2009), ajudam a compreender o marketing viral, comportamento do consumidor e sua propenção a compartilhar conteúdo.

\section{Metodologia}

A investigação assume uma natureza de caráter descritiva. Neste tipo de pesquisa o principal objetivo é relatar características de uma determinada população ou fenômeno, ou ainda estabelecer relação entre variáveis (GIL, 2002). Foi utilizada abordagem quantitativa, que para Creswell (2010), corresponde à um meio de testar teorias objetivas, explorando a relação entre variáveis.

A unidade de análise foi constituída por uma população de indivíduos pertencentes à rede de contatos dos pesquisadores, sendo, portanto, empregada uma amostragem não probabilística, utilizando técnica de levantamento de dados survey.

O instrumento escolhido foi o questionário, tendo em vista a busca pelo entendimento da influência do Marketing Viral na decisão de compra dos consumidores jovens. Esse método foi composto por uma série de perguntas dispostas de forma ordenada que deveriam ser respondidas sem a presença do pesquisador. Tal técnica para coletar dados pode apresentar vantagens como maior liberdade para os respondentes devido ao anonimato, além de alcançar uma maior área geográfica, resultando em respostas mais rápidas e precisas (MARCONI; LAKATOS, 2003).

O questionário foi elaborado a partir do Google Docs, utilizado para a obtenção dos dados. Tal instrumento é resultante da combinação de três modelos propostos, primeiramente concebido por Fairbank (2008) através de um questionário que teve como foco a análise da eficácia do marketing viral e sua relação com as vendas. Em seguida o de Jakobsen e Skov (2009) que propuseram um experimento com dois vídeos, objetivando verificar se um vídeo viral está mais suscetível a ser compartilhado se produzido por um usuário comum ou por um 
profissional. Por fim, o de Xavier e Summer (2009) colaboraram com uma investigação sobre a receptividade, percepção e resposta comportamental do consumidor relacionados ao marketing viral.

O questionário foi composto por dez questões de múltipla escolha, dezesseis questões formadas através de uma escala de likert, onde o respondente teve a oportunidade de manifestar o seu grau de concordância ou discordância quanto as afirmações apresentadas e dezesseis do tipo diferencial semântica, onde as respostas foram representadas por adjetivos opostos através de uma escala com sete níveis. Para a sua construção foi desenvolvida uma estrutura lógica dividida em três partes. A primeira parte aborda as motivações da pesquisa e ainda instrui os respondentes sobre o instrumento utilizado. Além disso, solicitou-se alguns dados demográficos e o e-mail como forma de se evitar duplicidade. Visando identificar o grau de envolvimento destes com a internet e seus recursos, foram desenvolvidas perguntas inerentes a sua utilização, como frequência e tempo de uso.

Na busca pelo entendimento da percepção dos consumidores com relação à campanhas de publicidade, a segunda parte foi direcionada na mensuração do grau de atitude destes respondentes sobre propagandas de um modo geral, compartilhamento de informações através da internet e nível de envolvimento com o produto, que neste caso trata-se de um smartphone da marca Apple.

Por fim, na terceira parte, os respondentes tiveram acesso a um vídeo promocional deste smartphone, disponibilizado no próprio questionário do Google Docs, e, após sua visualização, preencheram questões com variáveis associadas à peça publicitária, como: atitude, qualidade, disseminação e lealdade.

Com relação a análise das médias foram considerados os seguintes níveis: de 1,0 à 2,9 inferior (INF); de 3,0 à 4,9 intermediário (INT); e de 5,0 à 7,0 superior (SUP). Assim, de acordo com os níveis INF, INT e SUP escolhidos através da quantidade de respondentes, a amostra total foi classificada e analisada.

Foram enviados 221 questionários, obteve-se uma taxa de resposta de 24\%, correspondendo a um total de 53.

\section{Resultados}

A amostra é composta por uma pequena maioria de $54,7 \%$ do sexo feminino, idade média de 24 anos, $62,5 \%$ até 25 anos, a maioria de $71,6 \%$ é dividida equitativamente entre pessoas que estão no ensino superior ou trabalham em empresas privadas.

Verificou-se que a maioria de $98,1 \%$ utiliza a internet todos os dias da semana, sendo que $41,5 \%$ estão conectados de 10 a 19 horas por semana e $18,9 \%$ por mais de 50 .

Estes resultados, assim como as outras pesquisas realizadas nessa perspectiva da conectividade (ex.: IBGE, 2016; IBGE, 2018; FTV, 2019; AHLGREN, 2020; INTERNET WORLD STATS, 2020), evidenciam o seu crescimento constante e o papel que a internet tem assumido na vida das pessoas e dos negócios. A internet e outros tipos de tecnologia transformaram a maneira como as pessoas se comportam, interagem, se comunicam e compram. A expansão da 
internet e conectividade constante motivou o surgimento de um novo perfil de consumidor que não pode ser ignorado, seu poder está relacionado a quatro fontes: (1) tecnológico - direito de ser ouvido; (2) econômico - direito de escolha; (3) social - direito a ser informado; e (4) legal direito à segurança (GRUBOR; JAKŠA, 2018).

Além de compartilhar informações sobre produtos e serviços que utilizam, são altamente atraídos por várias opções para compartilhar informações sobre si mesmos. Os consumidores online são muito exigentes em termos de satisfação com a comunicação de marketing e experiência com os produtos e serviços que utilizam (GRUBOR; JAKŠA, 2018). Procuram conteúdo especial, diferente e hiper personalizado o tempo todo, de acordo com seu estilo de vida e a autoimagem ideal. Usam todas as opções e contatos online para descobrir a melhor solução para seus interesses, sendo esse, um dos fatores que explicam a necessidade de se utilizar as redes sociais (MARQUES; VIDIGAL, 2018).

Buscando investigar o tempo de uso com e-mail, Youtube, WhatsApp, Facebook, Twitter e Instagram, alguns dos principais canais do marketing da internet (GRUBOR; JAKŠA, 2018), verificou-se que 45,3\% utiliza o e-mail por menos de 1 hora por semana e apenas 5,7\% informaram não utilizam. Quanto ao Youtube, 45,3\% utilizam o recurso entre 1 e 8 horas por semana, revelando a grande importância desta plataforma na difusão de vídeos pela internet, sendo esta a que detém o maior número de influenciadores (DINH et al., 2014).

Entre as mídias analisadas o grande destaque foi para o WhatsApp, onde 51\% dos pesquisados informaram usar a ferramenta acima de 16 horas por semana. O que demonstra a relevância deste novo canal de comunicação no compartilhamento e disseminação de conteúdo entre as pessoas. Esses resultados corroboram com a pesquisa da FTV (2019), que o apresenta como sendo a principal mídia utilizada por $98 \%$ dos pesquisados, com uma frequência média de utilização de 6,2 dias por semana, ainda a pesquisa trouxe os principais motivos dessa adesão: principal meio para se relacionar com familiares e amigos (1); nos grupos de conversas chegam os memes, as fofocas e os convites para as festas e reuniões (2); muito utilizado para o trabalho (3).

Os demais resultados encontrados revelam que o tempo de uso com o Facebook e Instagram apresentaram resultados aproximados, $39,9 \%$ e $32 \%$, respectivamente, passando entre 1 e 8 horas por semana com as ferramentas, o que destaca maior popularidade destas redes perante às outras. No entanto, é importante destacar que os usuários despendem mais tempo no Instagram, assim $45 \%$ dos pesquisados pode passar mais de $9 \mathrm{~h}$ por semana nessa plataforma. Quanto ao Twitter, a grande maioria de 74\% não utilizam, ver Tabela 01.

Observou-se na amostra, uma tendência por utilizar mídias que possibilitem um maior engajamento com grupos semelhantes. Como a maioria dos sujeitos da pesquisa são jovens, o Instagram passou a ser uma das mais utilizadas e por mais tempo, isso pode ser explicado pela pesquisa da FTV (2019), que a apresenta como a "queridinha" desse público, visto que boa parte dos colegas e membros da família "indesejados" ainda não a utilizam. Enquanto o Facebook, foi apresentado como uma questão de necessidade, visto que algumas empresas analisam os candidatos pelo seu perfil na rede. 
Tabela 01: Tempo de uso com E'mail, Youtube, WhatsApp, Facebook, Twitter e Instagram.

\begin{tabular}{c|c|c|c|c|c|c}
\hline Tempo de uso & E-mail & Youtube & Whats App & Facebook & Twitter & Instagram \\
\hline Não uso & $5,7 \%$ & $0 \%$ & $0 \%$ & $15 \%$ & $74 \%$ & $11 \%$ \\
\hline Menos de 1h por semana & $45,2 \%$ & $24,5 \%$ & $0 \%$ & $20,7 \%$ & $17 \%$ & $11 \%$ \\
\hline Entre 1-8hs por semana & $32,1 \%$ & $45,3 \%$ & $22,6 \%$ & $39,6 \%$ & $6 \%$ & $32 \%$ \\
\hline Entre 9-16hs por semana & $13,2 \%$ & $18,9 \%$ & $26,4 \%$ & $18,9 \%$ & $4 \%$ & $26 \%$ \\
\hline Acima de 16hs por semana & $3,8 \%$ & $11,4 \%$ & $51 \%$ & $5,7 \%$ & $0 \%$ & $19 \%$ \\
\hline
\end{tabular}

Fonte: Pesquisa direta (2018).

O e-mail, mesmo apresentar do um baixo tempo de uso, para 45,3\% é menos de uma hora, é um importante canal de marketing, Grubor e Jakša (2018), o apresentam como um caminho direto para a comunicação pessoal e personalizada com clientes novos e antigos, esses tipos de campanhas são econômicas, personalizadas, rápidas, massivas, mas direcionadas, aprovadas por consumidores que geralmente são conscientemente registradas na lista das empresas.

Pesquisa realizada pelo Pew Research Center (2018) com jovens americanos de 18 a 24 anos, confirma esta sequência de popularidade entre estas redes sociais, onde Facebook obteve $80 \%$, Instagram $71 \%$ e Twitter 45\%. Neste contexto, Bueno (2020) apresentou as redes sociais mais utilizadas pelos brasileiros em 2019, sendo o Youtube a mais utilizada com adesão de 95\% dos brasileiros, ultrapassando o Facebook. O que pode ser explicado pela relevância do formato, no Instagram, esse tipo de formato recebe $38 \%$ a mais de engajamento e duas vezes mais comentários que uma foto (BUENO, 2020).

É importante investigar os meios tecnológicos que possibilitam esse engajamento e constante conectividade, assim pretendeu-se investigar qual seria o equipamento mais utilizado para tal acesso. Os resultados obtidos foram os seguintes: 79,2\% informaram utilizar o smartphone, enquanto $20,8 \%$ usam PC ou notebook, no entanto não houve nenhuma resposta para uso do Tablet ou Smart TV para acesso.

Entende-se que o smartphone se destaque por ser um equipamento com grandes funcionalidades, e, devido ao seu tamanho reduzido, está sempre ao alcance das pessoas, e possa ser facilmente transportado. Esses resultados estão em concordância com a pesquisa desenvolvida pelo IBGE (2018), onde esse foi o meio mais utilizado para acessar a internet. A este respeito, Kotler, Kartajaya e Setiawan (2017), apresentam a dependência dos usuários desse equipamento para a realização de diversas atividades do seu dia a dia.

Considerando, a facilidade possibilitada pela internet e os diversos meios que a precedem, para as empresas estarem em contato com os seus clientes potenciais, buscou-se o entendimento sobre o grau de confiança, como também a percepção dos respondentes quanto às propagandas.

Os resultados encontrados para as variáveis relacionadas à atitude em relação às propagandas foram: houve concordância em nível intermediário quanto à crença nas propagandas, que elas devem ser fontes confiáveis de informação, que apresentam uma imagem fiel do produto anunciado e sentem-se bem informados ao verem a maioria dos anúncios. De acordo com a variável referente a percepção de que o objetivo das propagandas deve ser informar, a grande maioria concorda em nível superior, ver Tabela 02. 
Tabela 02: Atitude em relação às propagandas.

\begin{tabular}{c|c|c|c|c}
\multirow{2}{*}{ Variáveis } & \multicolumn{4}{|c}{ Amostra Total } \\
\cline { 2 - 5 } & INF & INT & SUP & Média \\
\hline Crença na Propaganda & $30,2 \%$ & $49,0 \%$ & $20,8 \%$ & 3,3 \\
\hline Informar o Consumidor & $17,0 \%$ & $49,0 \%$ & $34,0 \%$ & 4,0 \\
\hline Propaganda Informativa & $0,0 \%$ & $18,9 \%$ & $81,1 \%$ & 5,6 \\
\hline Veracidade da Propaganda & $18,9 \%$ & $54,7 \%$ & $26,4 \%$ & 3,7 \\
\hline Confiança nas informações & $24,5 \%$ & $58,5 \%$ & $17,0 \%$ & 3,3 \\
\hline Imagem Fiel & $18,9 \%$ & $62,2 \%$ & $18,9 \%$ & 3,4 \\
\hline Nível de Informação & $28,3 \%$ & $43,4 \%$ & $28,3 \%$ & 3,4 \\
\hline
\end{tabular}

Fonte: Pesquisa direta (2018).

Neste sentido, Kotler, Kartajaya e Setiawan (2017) esclarecem que hoje os consumidores não confiam nas propagandas como no passado, mas sim, no fator social, opiniões dos amigos, família, seguidores do Facebook e do Twitter. Os consumidores online são muito exigentes em termos de satisfação com a comunicação de marketing e experiência com os produtos e serviços que utilizam, esses procuram o conteúdo especial, utilizando de todas as opções online para descobrir a melhor solução para seus interesses (GRUBOR; JAKŠA, 2018).

A função da propaganda é diferenciar um produto e posicioná-lo na mente do consumidor de forma distinta dos concorrentes, no entanto, a internet vem revolucionando esse canal e exigindo das empresas maiores investimentos em tecnologia, de forma a se aproximar mais dos consumidores, desenvolvendo campanhas mais interativas (COBRA, 2009).

Dando importância, a essa nova configuração em redes da sociedade, buscou-se analisar o grau de atitude dos respondentes quanto ao compartilhamento de conteúdo na internet. Os resultados revelaram que a maioria concorda em nível superior quanto à importância em avaliar as experiências de outros consumidores antes de adquirir um produto/serviço. Sentem-se mais afetados por comentários negativos do que positivos em suas escolhas, estão mais inclinados a realizar compras quando as informações virem de pessoas conhecidas. Antes de adquirir um produto/serviço pesquisam na internet e ainda acreditam que a recomendação advinda reforça a convicção e empenho com relação a uma determinada marca de um produto/serviço. Ver Tabela 03.

Tabela 03: Atitude de compartilhamento de informações via internet.

\begin{tabular}{c|c|c|c|c}
\multirow{2}{*}{ Variáveis } & \multicolumn{4}{|c}{ Amostra Total } \\
\cline { 2 - 5 } & INF & INT & SUP & Média \\
\hline Confiança nos comentários & $26,4 \%$ & $35,8 \%$ & $37,8 \%$ & 3,6 \\
\hline Experiência de consumidores & $0,0 \%$ & $1,9 \%$ & $98,1 \%$ & 6,5 \\
\hline Efeito dos comentários & $1,9 \%$ & $26,4 \%$ & $71,7 \%$ & 5,3 \\
\hline Mensagem de conhecidos & $5,7 \%$ & $7,5 \%$ & $86,8 \%$ & 5,7 \\
\hline Busca de informações & $0,0 \%$ & $5,7 \%$ & $94,3 \%$ & 6,5 \\
\hline Convicção na marca & $3,8 \%$ & $5,6 \%$ & $90,6 \%$ & 5,8 \\
\hline
\end{tabular}

Fonte: Pesquisa direta (2018)

Quanto aos respondentes serem mais afetados por comentários negativos antes de adquirir algum produto/serviço, percebe-se que os resultados corroboram com a pesquisa de Xavier 
e Summer (2009), onde 60\% mencionam que comentários negativos podem evitar compras por impulso e compras de produtos com qualidade duvidosa. Contudo, Kotler, Kartajaya e Setiawan (2017), afirmam que nem sempre os comentários negativos são ruins, pois a partir deles pode-se ativar defesas positivas.

A desconfiança em mensagens publicitárias muito boas, levam a indiferença dos clientes e estes preterem as informações mais confiáveis provenientes de familiares e amigos (KOTLER, KARTAJAYA; SETIAWAN, 2017). Deste modo, em conformidade com este resultado, Fairbank (2008), mostrou em seu estudo que há uma certa desconfiança em opiniões online quando provindas de desconhecidos.

Por meio das variáveis importância do produto, conhecimento do produto e uso do produto, buscou-se verificar o grau de ligação dos respondentes com o produto escolhido para esta pesquisa (smartphone). Os resultados obtidos para as variáveis associadas ao envolvimento com o produto foram os seguintes: houve uma concordância em nível superior, quanto à importância dos smartphones, conhecimento sobre eles e frequência de uso, ver Tabela 04.

Tabela 04: Envolvimento com o produto.

\begin{tabular}{c|c|c|c|c}
\multirow{2}{*}{ Variáveis } & \multicolumn{3}{|c}{ Amostra Total } \\
\cline { 2 - 5 } & INF & INT & SUP & Média \\
\hline Importância do produto & $0,0 \%$ & $5,7 \%$ & $94,3 \%$ & 6,4 \\
\hline Conhecimento do produto & $0,0 \%$ & $22,5 \%$ & $77,4 \%$ & 5,2 \\
\hline Uso do produto & $0,0 \%$ & $3,8 \%$ & $96,2 \%$ & 6,5 \\
\hline
\end{tabular}

Fonte: Pesquisa direta (2018)

De acordo com Kotler, Kartajaya e Setiawan (2017), este ritmo acelerado trazido pela mobilidade está diretamente ligado ao jovem e a sua impaciência, onde tudo deve ser instantâneo e a qualquer momento recorrem a seus dispositivos móveis na busca por informações. Esta tendência já havia sido observada pelo IBGE (2018), no qual o smartphone foi o dispositivo mais utilizado para acessar a internet, com $97 \%$.

Pretendeu-se também identificar o nível de relação dos respondentes com a marca analisada (Apple). Os resultados revelaram que a maioria concorda em nível superior quanto ao conhecimento e percepção da marca, ver Tabela 05.

Tabela 05: Envolvimento com a marca.

\begin{tabular}{c|c|c|c|c}
\multirow{2}{*}{ Variáveis } & \multicolumn{4}{|c}{ Amostra Total } \\
\cline { 2 - 5 } & INF & INT & SUP & Média \\
\hline Conhecimento da marca & $17,0 \%$ & $28,3 \%$ & $54,7 \%$ & 4,5 \\
\hline Percepção da marca & $0,0 \%$ & $20,8 \%$ & $79,2 \%$ & 5,7 \\
\hline
\end{tabular}

Fonte: Pesquisa direta (2018)

Sendo a percepção o processo onde as pessoas utilizam das informações adquiridas para criar uma imagem e opinião acerca de determinado objeto, pessoa ou marca; sendo algo subjetivo e resultado de estímulos, resultando em crenças e atitudes que influenciarão no comportamento de compra (KOTLER, KARTAJAYA; SETIAWAN, 2017). Ainda, os autores acrescentam que no mundo conectado, os clientes quando entendem a marca se conectam ativamente a ela, e passam a desenvolver sentimentos sendo capazes de defende-la. Desta forma, estes resultados 
sugerem que, além de notoriedade e qualidade associados à marca, também a possibilidade de sua defesa perante os contatos.

Após a visualização da peça publicitária, percebeu-se que a grande maioria de $86,8 \%$ desconhece o vídeo, enquanto apenas 13,2\% alegaram ter conhecimento sobre ela. Este resultado surpreende, haja vista a notoriedade da marca em questão (Apple), e ainda que, atualmente o acesso à conteúdo desta natureza tem sido bastante facilitado e difundido através da internet.

Para investigar o nível de percepção quanto à peça publicitária visualizada, os sujeitos apresentaram seu grau de atitude quanto a percepção, impressão, inovação, criatividade, diversão e entretenimento do vídeo.

Assim, os resultados demonstraram que a grande maioria concorda em nível superior quanto à percepção, superioridade, inovação, criatividade, diversão e entretenimento do vídeo. Sendo a variável criatividade aquela em que apresentou o maior percentual, ver Tabela 06.

Tabela 06: Atitude em relação ao vídeo.

\begin{tabular}{c|c|c|c|c}
\multirow{2}{*}{ Variáveis } & \multicolumn{4}{|c}{ Amostra Total } \\
\cline { 2 - 5 } & INF & INT & SUP & Média \\
\hline Percepção do vídeo & $5,6 \%$ & $30,2 \%$ & $64,2 \%$ & 5,2 \\
\hline Impressão do vídeo & $1,9 \%$ & $20,8 \%$ & $77,3 \%$ & 5,5 \\
\hline Inovação do vídeo & $1,9 \%$ & $18,9 \%$ & $79,2 \%$ & 5,4 \\
\hline Criatividade do vídeo & $1,9 \%$ & $13,2 \%$ & $84,9 \%$ & 5,7 \\
\hline Diversão do vídeo & $5,6 \%$ & $18,9 \%$ & $75,5 \%$ & 5,3 \\
\hline Entretenimento do vídeo & $3,8 \%$ & $17,0 \%$ & $79,2 \%$ & 5,4 \\
\hline
\end{tabular}

Fonte: Pesquisa direta (2018)

A criatividade é uma característica fundamental para viralização de vídeos, além disso, outros fatores também podem influenciar diretamente para o sucesso de compartilhamento, como: vídeos mais curtos, com conteúdo familiar, engraçados e que contenham música terão maiores chances de se tornarem viral (JENDOUBI; MARTIN, 2020). O sucesso dessa peça publicitária se confirma em números através do site de compartilhamento de vídeos Youtube, que após ser postado pela empresa Apple em julho de 2018, ultrapassou oito milhões de acessos, demonstrando além de grande popularidade, também potencial para viralização.

Quanto a qualidade do vídeo, todos os resultados se apresentaram como maioria em nível superior: percepção da qualidade da peça publicitária, grau de profissionalismo e grau de sofisticação, ver Tabela 08.

Tabela 08: Qualidade do vídeo

\begin{tabular}{c|c|c|c|c}
\multirow{2}{*}{ Variáveis } & \multicolumn{3}{|c}{ Amostra Total } & Média \\
\cline { 2 - 5 } & INF & INT & SUP & 6,3 \\
\hline Percepção da qualidade & $0,0 \%$ & $5,7 \%$ & $94,3 \%$ & 6,4 \\
\hline Grau de profissionalismo & $1,9 \%$ & $5,7 \%$ & $92,4 \%$ & 6,1 \\
\hline Grau de sofisticação & $0,0 \%$ & $9,4 \%$ & $90,6 \%$ & \\
\hline
\end{tabular}

Fonte: Pesquisa direta(2018) 
Assim, a qualidade do vídeo foi um atributo relevante, fato este também observado por Jakobsen e Skov (2009) em seu estudo que visou analisar a percepção dos usuários em diferenciar um vídeo produzido por um profissional de um produzido através de um usuário da internet. Nesses resultados, mesmo sem saber qual produção era a profissional ou a amadora, os respondentes atribuíram maior qualidade à produção realizada por um especialista e menor qualidade à produção realizada por um amador.

Buscando entender o grau de inclinação dos consumidores quanto ao compartilhamento de comentários e disseminação do vídeo na internet, as variáveis associadas à disseminação de comentários, demonstraram que a maioria concorda a nível intermediário quanto à disposição em falar sobre o vídeo para sua rede de contatos e ainda disseminá-lo entre eles. Contudo, quando questionados quanto a comentar positivamente sobre o vídeo, os resultados se aproximaram do nível superior, o que demonstra certa empatia com a peça apresentada, verificando-se a possibilidade de disseminação deste conteúdo, ver Tabela 09.

Tabela 09: Disseminação de comentários

\begin{tabular}{c|c|c|c|c}
\multirow{2}{*}{ Variáveis } & \multicolumn{4}{|c}{ Amostra Total } \\
\cline { 2 - 5 } & INF & INT & SUP & Média \\
\hline Ímpeto de disseminação & $26,4 \%$ & $41,5 \%$ & $32,1 \%$ & 3,7 \\
\hline Propagação de comentários & $15,1 \%$ & $30,2 \%$ & $54,7 \%$ & 4,5 \\
\hline Disseminação do vídeo & $28,3 \%$ & $41,5 \%$ & $30,2 \%$ & 3,7 \\
\hline
\end{tabular}

Fonte: Pesquisa direta (2018)

A aversão em disseminar, pode estar associada ao aumento expresivo de conteúdos propagados na internet pelas empresas, a partir da popularização da conectividade e mobilidade (KOTLER, KARTAJAYA; SETIAWAN, 2017). Assim, os consumidores se veem sobrecarregados de características de produtos, promessas de marcas e argumentos de vendas, o que costumeiramente resulta em rejeição por parte deles.

Ao relacionar as variáveis associadas à disseminação de comentários e idade, os resultados foram os seguintes: na categoria até 20 anos, há uma mudança de percepção quanto ao compartilhamento e disseminação de conteúdo através da internet, indicando que os jovens desta faixa etária concordam a nível superior com relação à disposição em compartilhar e disseminar conteúdo, ver Figura 01.

Figura 01: Relação entre disseminação de comentários e idade.

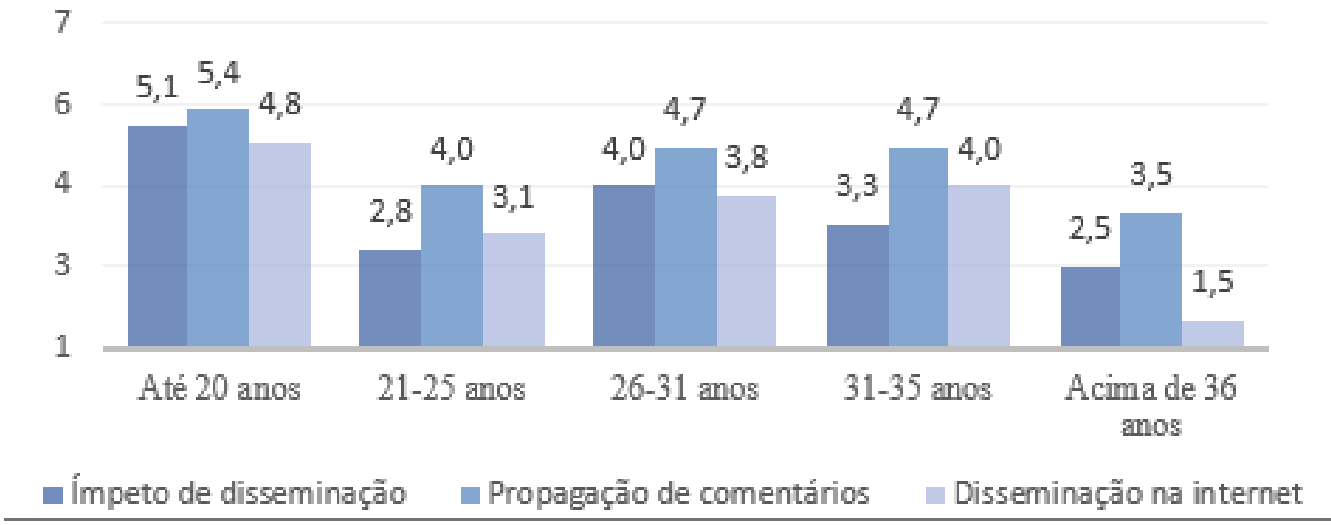

Fonte: Pesquisa direta 
Nesta perspectiva a conectividade está fortemente ligada aos jovens, eles são adotantes iniciais de produtos/serviço e potenciais influenciadores de novas tendências (KOTLER; KARTAJAYA; SETIAWAN, 2017; JIN; RYU, 2019; FARD; MARVI, 2020). Assim, observa-se a importância deste público jovem em influenciar outras pessoas através da internet.

A partir das variáveis intensão de compra, recomendação de marca e fatores que motivam a divulgação de mensagens, pretendeu-se identificar o grau de lealdade em relação ao produto, bem como investigar, os fatores que levam as pessoas a divulgar conteúdos através da internet. Ver Tabela 10 e Figura 03.

Os resultados encontrados para as variáveis associadas à lealdade do produto foram: após a visualização do vídeo os respondentes concordam a um nível intermediário quanto a intensão de compra e recomendação de marca.

Tabela 10: Lealdade ao produto.

\begin{tabular}{c|c|c|c|c}
\multirow{2}{*}{ Variáveis } & \multicolumn{4}{|c}{ Amostra Total } \\
\cline { 2 - 5 } & INF & INT & SUP & Média \\
\hline Intenção de compra & $5,7 \%$ & $54,7 \%$ & $39,6 \%$ & 4,8 \\
\hline Recomendação de marca & $9,4 \%$ & $41,5 \%$ & $49,1 \%$ & 4,5 \\
\hline
\end{tabular}

Fonte: Pesquisa direta (2018)

A atração pela marca precisa de confirmação de outras pessoas para que o consumidor tome suas decisões, esta é a fase de arguição, que posteriormente os levará à ação de compra, desta forma o consumidor precisa obter informações adicionais de amigos, avaliações online do produto, comparação de preços e assim por diante (KOTLER; KARTAJAYA; SETIAWAN, 2017). Assim, ao decidir por comprar o produto, o consumidor, com o passar do tempo, pode desenvolver fidelidade à marca, recomprando-a e recomendando-a a seus contatos, o que se encaixaria na fase de apologia.

Ao relacionar as variáveis associadas à lealdade do produto e idade, os resultados encontrados foram os seguintes: na categoria até 20 anos, há uma mudança de percepção quanto à intensão de compra e recomendação de marca, indicando que os jovens desta faixa etária concordam a nível superior com relação à disposição em comprar e recomendar uma marca, ver Figura 02.

Figura 02: Relação entre lealdade ao produto e idade.

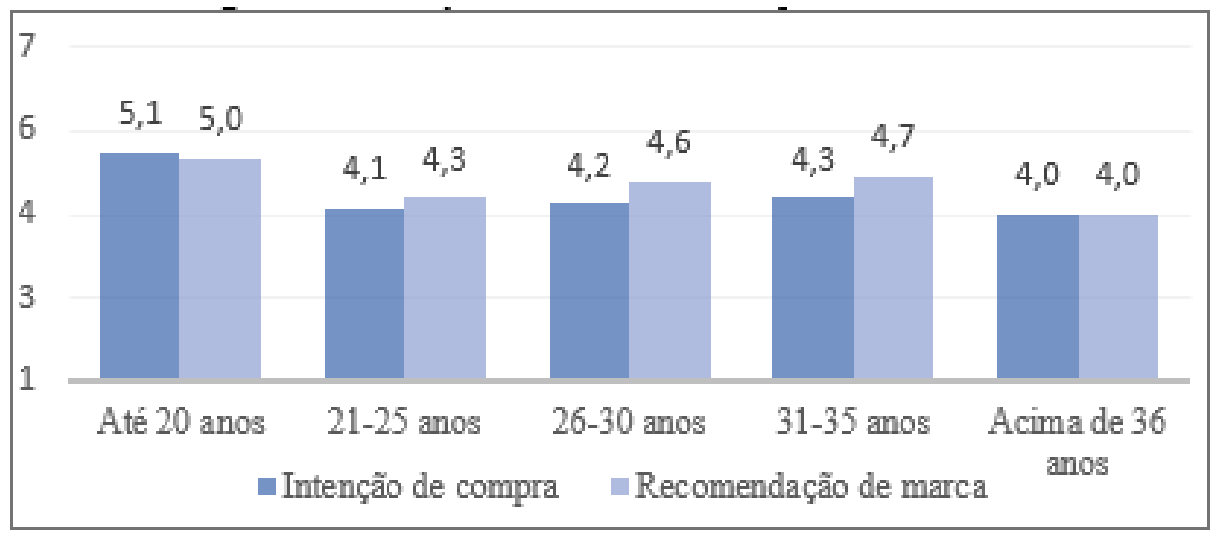

Fonte: Pesquisa direta (2018) 
É relevante ressaltar que as marcas devem concentrar seus esforços nos jovens, pois, como afirmam Kotler, Kartajaya e Setiawan (2017), estes formam uma população expressiva no mundo, são o futuro e provavelmente os clientes mais rentáveis. Estes resultados demonstram superioridade quanto ao grau de inclinação desses consumidores jovens em comprar e recomendar uma marca através da internet.

Os resultados apresentados para as variáveis associadas aos fatores motivacionais foram os seguintes: a maioria dos respondentes admitiram que a diversão está entre as principais motivações em divulgar mensagens através da internet, ver Figura 03. Estes resultados corroboram com os achados de Xavier e Summer (2009), onde, a maioria costuma espalhar conteúdos divertidos e de caráter provocativo.

Figura 03: Fatores motivacionais.

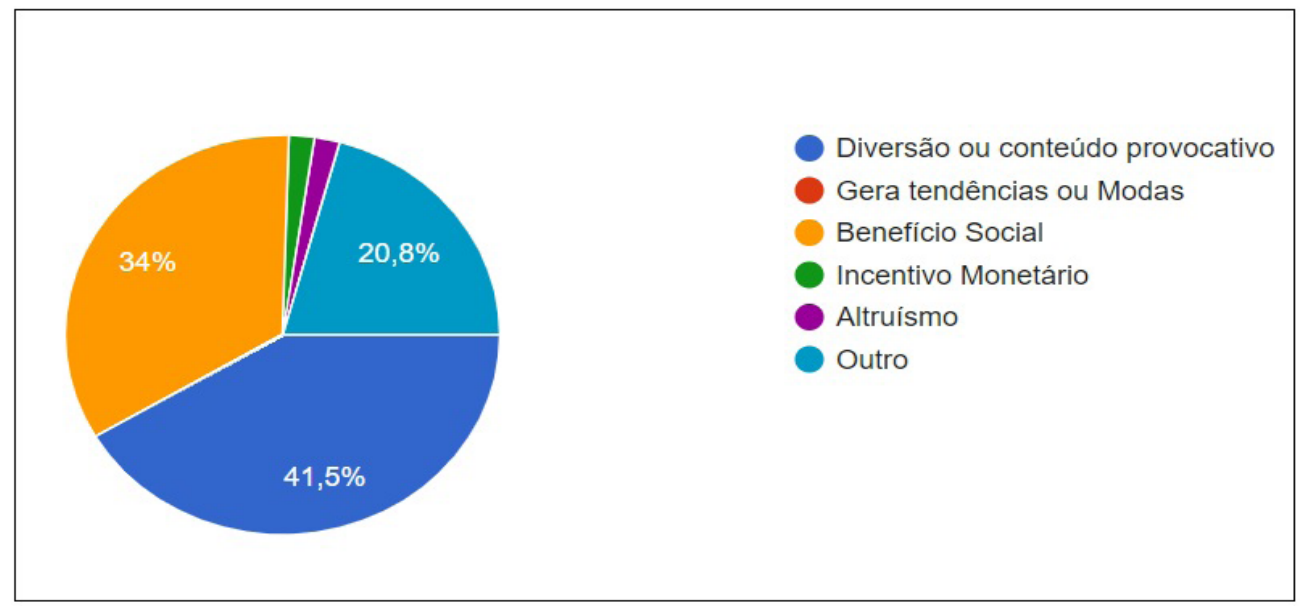

Fonte: Pesquisa direta(2018)

Outra observação interessante nos resultados, foram os 34\% que escolheram o benefício social como influenciador na divulgação de conteúdo. Assim, devido a conectividade, Kotler, Kartajaya e Setiawan (2017) afirmam que os consumidores possuem hoje um maior desejo de conformidade social em suas escolhas, eles se importam cada vez mais com as opiniões dos outros e constroem suas imagens de marcas e produtos através da socialização de informações de seus contatos.

\section{Conclusão}

Observou-se na pesquisa que a marca analisada, apresentou grande representatividade entre os participantes do estudo. Ao vídeo da marca apresentado foram atribuídas características como superioridade, inovação, diversão, criatividade e entretenimento. Os resultados encontrados sugerem que a peça publicitária em questão, apresenta potencialidade em ser compartilhada e disseminada através da internet.

Também foi possível identificar entre os mais jovens, uma maior propensão em compartilhar e disseminar conteúdo através da internet, bem como uma maior inclinação quanto à intensão de compra e recomendação de marca por parte desse grupo. Estes resultados apontam que há potencial no público mais jovem no processo de influência de conteúdo.

Verifica-se que o marketing viral tem emergido como uma ferramenta estratégica efe- 
tiva na divulgação de conteúdos através da internet, pois replica-se rapidamente e a ele incorre menores custos, quando comparado à mídia tradicional. Percebeu-se também a sua relevância em influenciar nas decisões de compras e divulgação de marca, principalmente entre o público mais jovem. No entanto, conteúdos que apresentem a marca de forma discreta, informem o consumidor de maneira honesta e ainda priorizem qualidade, diversão e criatividade, apresentam maior chance de obter sucesso em campanhas virais.

De maneira geral, a popularização do smartphone e das várias ferramentas da Tecnologia de Informação, a exemplo das redes sociais, e-commerce, e-mail e os mais diversos aplicativos, vêm proporcionando um significativo e marcante impacto no comportamento das pessoas. Entre essas mudanças comportamentais, proporcionadas pela massificação das comunicações em todos os sentidos, ressalta-se empoderamento das pessoas e isso pode explicar o desprestígio das comunicações empresariais veiculadas por exemplo, propagandas de marca, em relação as mensagens de amigos e familiares sobre os mesmos produtos.

\section{REFERÊNCIAS}

AHLGREN, M. 100 + estatísticas e fatos da internet para 2020. HostingRating, 2020. Disponível em: < https://www.websitehostingrating.com/pt/internet-statistics-facts/>. Acesso em: 27 de jun. 2020.

AL ABRI, D.; VALAEE, S. Diversified viral marketing: The power of sharing over multiple online social networks. Knowledge-Based Systems, v. 193, 2019. DOI: https://doi.org/10.1016/j. knosys.2019.105430.

BAIERLE, I. C.; SELLITTO, M. A.; FROZZA, R.; SCHAEFER, J. L.; HABEKOST, A. F. An artificial intelligence and knowledge-based system to support the decision-making process in sales. South African Journal of Industrial Engineering, v. 30, n. 2, p. 17-25, 2019. DOI: http:// dx.doi.org/10.7166/30-2-1964

BASS, F. M. The future of research in marketing: Marketing science. Journal of Marketing Research, v. 30, n. 1, p. 1-6, 1993.

BICKART, B; SCHINDLER, R.M. Internet forums as influential sources of consumer information, Journal of Interactive Marketing, v. 15, n. 3, p. 31-40, 2001

BLATTBERG, R. C.; GLAZER, R.; LITTLE, J. D. C. The marketing information revolution. Boston, MA: Harvard Business School Press, 1994.

BUENO, M. As redes sociais mais usadas em 2020: As 20 tendências que você não pode ignorar. Alaska Marketing Digital, 2020. Disponível em: $<$ https://marketingconteudo.com/as-redessociais-mais-usadas-em-2020/>. Acesso em: 8 de jul. 2020.

CAPON, N.; GLAZER, R. Marketing and technology: A strategic coalignment. Journal of Marketing, v. 51, n. 3, p. 1-14, 1987. 
CAVALLINI, R. O Marketing depois de amanhã. São Paulo: Ed. do Autor, 2008.

COBRA, M. Administração de marketing no Brasil. $3^{\text {a }}$ Ed. Rio de Janeiro: Elsevier, 2009.

CRESWELL, J. W. Projeto de pesquisa: métodos qualitativo, quantitativo e misto. $3^{\text {a }}$ Ed. Porto Alegre: Artmed, 2010.

Digital 2020 Global digital overview: essential insights into how people around the world use the internet, mobile devices, social media and ecommerce. We are Social, 2020. Disponível em: $<$ https://wearesocial.com/digital-2020>. Acesso em: 1 de jul. 2020.

DINH, T.; ZHANG, H.; NGUYEN, D.; THAI, M. Cost-effective viral marketing for timecritical Campaigns in large-scale social networks. IEEE/ACM Trans. Netw., v. 22, n. 6, p. 2001-2011, 2014. DOI: http://dx.doi.org/10.1109/TNET.2013.2290714

FAIRBANK, V. A study into the effectiveness of viral marketing over the internet. 2008. Dissertação, University of Gloucestershire, Reino Unido.

FARD, M. H.; MARVI, R. Viral marketing and purchase intentions of mobile applications users. International Journal of Emerging Markets, v. 15, n. 2, p. 287-301, 2020. DOI: 10.1108/ IJOEM-06-2018-0291

FRANCISCO, E. R.; KUGLER, J. L.; KANG, S. M.; SILVA, R.; WHIGHAM, P. A. Além da tecnologia: Desafios gerenciais na era do Big Data. RAE-Revista de Administração de Empresas, v. 59, n. 6, p. 375-378, 2019.

FTV. Juventudes e Conexões. 3.ed. São Paulo: Fundação Telefônica Vivo, 2019.

GIL, A. C. Como elaborar projetos de pesquisa. 4ª Ed. São Paulo: Atlas, 2002.

GODIN, S. Isso é Marketing: Para ser Visto é Preciso Aprender a Enxergar. $1^{\text {a }}$ Ed. São Paulo: Editora Alta Books, 2019.

GRUBOR, A.; JAKŠA, O. Internet marketing as a Business necessity. Interdisciplinary Description of Complex Systems, v. 16, n. 2, p. 265-274, 2018. DOI: 10.7906/indecs.16.2.6

HO, Y.C.; DEMPSEY, M. Viral marketing: motivation to forward online content. Journal of Business Research, v. 63, nos. 9-10, p. 1000-1006, 2010.

IANSITI, M.; LAKHANI, K.R. A competição na era da IA. Harvard Business Review, v. 98, n. 2, p. 38-45, 2020.

IBGE. Pesquisa Nacional por Amostra de Domicílios (PNAD), 2016. Disponível em: $<$ http:// www.ibge.gov.br>. Acesso em: 20 de jul. 2018.

IBGE. Acesso à internet e à televisão e posse de telefone móvel celular para uso pessoal. 
Informativo da PNAD Contínua, 2018. Disponível em: <https:// biblioteca.ibge.gov.br/ visualizacao/livros/liv101631_informativo.pdf>.

JAKOBSEN, J.; SKOV, P. H. User created Ads in viral marketing. 2009. Dissertação (Msc. in Marketing), Aarhus School of Business, Dinamarca.

JENDOUBI, S.; MARTIN, A. Evidential positive opinion influence measures for viral marketing. Knowledge and Information Systems, v. 62, p. 1037-1062, 2020. DOI: https://doi. org/10.1007/s10115-019-01375-w

JIN, S. V.; RYU, E. Celebrity fashion brand endorsement in Facebook viral marketing and social commerce: Interactive effects of social identification, materialism, fashion involvement, and opinion leadership. Journal of Fashion Marketing and Management, v. 23, n. 1, p. 104123, 2019. DOI: 10.1108/JFMM-01-2018-0001

KOTLER, P.; KELLER, K. Administração de Marketing. 14a Ed. São Paulo: Pearson Education do Brasil, 2012.

KOTLER, P.; KARTAJAYA, H.; SETIAWAN, I. Marketing 4.0: do tradicional ao digital. Rio de Janeiro: Elsevier, 2017.

KRUGMAN, D.M.; RUST, R. T. The impact of cable and VCR penetration on network viewing: Assessing the decade. Journal of Advertising Research, v. 33, n. 1, p. 67-73, 1993.

LEEFLANG, P. S. H.; WITTINK, D. R. Building models for marketing decisions: Past, present and future. International Journal of Research in Marketing, v. 17, nos. 2-3, p. 105-126, 2000.

LIPSMAN, A. Ecommerce Continues Strong Gains Amid Global Economic Uncertainty. eMarketer. 27 de jun. 2019. Global Ecommerce 2019. Disponível em: $<$ https://www.emarketer. com/content/global-ecommerce-2019>. Acesso em: 27 de jun. 2020.

LOPEZ, M.; SICILIA, M. How WOM marketing contributes to new product adoption: Testing competitive communication strategies. European Journal of Marketing, v. 47, n.7, p. 10891114, 2013. DOI: https://doi.org/10.1108/03090561311324228

MARCONI, M. A; LAKATOS, E. M. Fundamentos de Metodologia Científica. $5^{\text {a }}$ ed. São Paulo: Atlas, 2003.

MSI. Research priorities 2016 - 2018. MARKETING SCIENCE INSTITUTE. Cambridge, 2016.

MARQUES, L. K. S.; VIDIGAL, F. Prosumers e redes sociais como fontes de informação mercadológica: uma análise sob a perspectiva da inteligência competitiva em empresas brasileiras. Transinformação, v. 30, n. 1, p. 1-14, 2018. DOI: https://doi.org/10.1590/231808892018000100001 
MORICI, R. V. Marketing no Brasil: brand equity, mídia e estatísticas. Rio de Janeiro: Elsevier, 2013.

PRIDE, W. M.; FERREL, O. C. Fundamentos de marketing. $6^{\text {a }}$ Ed. São Paulo: Cengage Learning, 2016.

REICHSTEIN, T.; BRUSCH, I. The decision-making process in viral marketing: A review and suggestions for further research. Psychol Mark, v. 36, p. 1062-1081, 2019. DOI: 10.1002/ mar.21256

REIS, A.; TROUT, J. Positioning: The Battle for Your Mind: How to Be Seen and Heard in the overcrowed marketplaced. Reimpressão. McGraw Hill Professional, 2001.

REVELA, A. Buyer Personas: How to Gain Insight Into Your Customer's Expectations, Align Your Marketing Strategies, and Win More Business. $1^{\text {a }}$ Ed. Wiley, 2015.

RUST, R. T. The future of marketing. International Journal of Research in Marketing, v. 37, p. 15-26, 2020. DOI: https://doi.org/10.1016/j.ijresmar.2019.08.002

RUST, R. T.; HUANG, M. H. The service revolution and the transformation of marketing science. Marketing Science, v. 33, n. 2, p. 206-221, 2014.

RUST, R. T.; MOORMAN, C.; BHALLA, G. Rethinking marketing. Harvard Business Review, v. 88, n. 1, p. 94-101, 2010.

SABAITYTĖ, J.; DAVIDAVIČIENĖ, V.; STRAKOVÁ, J.; RAUDELIŪNIENĖ, J. Decision tree modelling of e-consumers' preferences for Internet Marketing communication tools during browsing. Information Management, v. 22, n. 1, p. 206-221, 2019. DOI: 10.15240/tul/001/2019$1-014$

SAMIEE, S. International marketing and the internet: a research overview and the path forward, International Marketing Review, v. 37, n. 3, p. 425-436, 2020. DOI: https://doi.org/10.1108/ IMR-03-2018-0120

SANTOS, J. M. A. Inteligência Artificial, Machine Learning e Algoritmos: como estas tecnologias estão moldando o novo mercado da música. 2019. Dissertação. (Mestrado em Gestão da Economia Criativa) - Escola Superior de Propaganda e Marketing, Rio de Janeiro.

STEINHOFF, L.; ARLI, D.; WEAVEN, S.; KOZLENKOVA, I. V. Online relationship marketing. Journal of the Academy of Marketing Science, v. 47, p. 369-393, 2019. DOI: https://doi. org/10.1007/s11747-018-0621-6

TORRES, C. A bíblia do marketing digital: tudo o que você queria saber sobre marketing e publicidade na internet e não tinha a quem perguntar. São Paulo: Novatec, 2009.

Total number of Websites. Internet live stats, 2020. Disponível em: <https://www. 
internetlivestats.com/total-number-of-websites/\#trend>. Acesso em: 27 de jun. 2020.

XAVIER L. J. W.; SUMMER, G. Y. S. Viral marketing Communication: the internet wordof-mouth. 2009. Dissertation (Master thesis in Business Administration), School of Management Blekinge Institute of Technology, Suécia.

WINER, R. S. A framework for customer relationship management. California Management Review, v. 43, n. 4, p. 88-105, 2001.

World Internet Users and 2020 Population Stats. Internet World Stats, 2020. Disponível em: $<$ https://www.internetworldstats.com/stats.htm>. Acesso em: 27 de jun. 2020.

Youtube, Instagram and Snapchat are the most popular online platforms among tens 2018. Pew Research Center, 2018. Disponível em: <http://www.pewinternet.org/2018/05/31/teens-socialmedia-technology-2018/pi_2018-05-31_teenstech_0-01/>. Acesso em 22 de set. 2018. 